\title{
A WEBERIANIZAÇÃO DO MUNDO
}

\section{Sérgio da Mata}

Universidade Federal de Ouro Preto

Mariana - Minas Gerais - Brasil

Resenha do livro: KAISER, Michael $\&$ ROSENBACH, Harald (ed.). Max Weber in der Welt. Rezeption und Wirkung. Tübingen: Mohr Siebeck, 2014, 243 p.

Uma das mais sedutoras teses presentes na obra de Max Weber é a que postula um processo geral, inexorável, de racionalização do mundo. Vista de uma perspectiva brasileira, não é preciso dizer o quão ambiciosa, até mesmo quimérica, tal tese pode parecer. O virtual emperramento do nosso sistema político desde as grandes manifestações de junho de 2013 - com sua recusa explícita dos partidos e a denegação do direito de ir e vir como estratégia privilegiada de pressão dos grupos à margem (direita ou esquerda, pouco importa) do poder -, o caos das contas e da saúde pública, a recusa em encarar de frente o caráter finito dos recursos naturais, os níveis alarmantes de violência interpessoal, a crise de legitimidade de uma presidente recém-eleita, o autismo generalizado, tudo isso sugere que a perspectiva weberiana da história tem lá os seus limites.

\footnotetext{
* Professor do Departamento de História do Instituto de Ciências Humanas e Sociais. E-mail: sdmata@ichs.ufop.br
} 
Mas teria Weber dado um sentido literal à sua ideia da racionalização do mundo? Entre 1917 e 1919, ele acompanha atônito a derrota alemã na guerra, a renúncia do kaiser, a proclamação dos conselhos operários em diversas cidades alemãs e o caos político em seu país. Ele viu na democracia a única salvação possível, e sua última série de escritos lança luz, quando não por simples homologia, sobre os dilemas do Brasil contemporâneo. Weber constatava a ascensão da rua como o espaço privilegiado da política, e pressentia que se a revolução alemã tinha o potencial de mover o país, certamente não seria no rumo do socialismo, mas sim no da mais abjeta reação. Nos últimos parágrafos de Economia e sociedade, ele escreve que

um fator completamente irracional (...) é dado pelas "massas" não-organizadas: a democracia de rua. Esta é mais poderosa em países com um parlamento impotente ou politicamente desacreditado, e isto significa sobretudo: na ausência de partidos racionalmente organizados. Na Alemanha, (...) organizações como os sindicatos, mas também como o Partido Social-Democrata, constituem um contraponto muito importante ao atual domínio irracional da rua, típico de nações puramente plebiscitárias. ${ }^{1}$

Àquela altura Weber considerava o sistema político alemão ante bellum "completamente obsoleto". No início de 1919, em meio às reuniões da comissão que elaborou a Constituição da República de Weimar, Weber - então no auge de sua popularidade como erudito e homem público - advertia que caso se mantivessem intocadas as bases de tal sistema,

a democracia política e economicamente progressiva não terá nenhuma chance num futuro previsível. As eleições mostraram que, por toda a parte, os antigos políticos profissionais conseguiram, contrariamente à disposição dos eleitores, eliminar os homens que gozam de confiança dessas massas em favor de uma mercadoria política ultrapassada. Como resultado, as melhores cabeças têm se afastado de toda a política. ${ }^{2}$

Poderíamos continuar indefinidamente, apontando as homologias existentes entre a Alemanha de 1917-1919 e o Brasil de 2013-2016. Que Weber tenha avaliado aquela época com notável clareza talvez seja uma razão a mais para ver em sua obra um potencial de esclarecimento que nem de longe se poderia encontrar no marxismo tardio de um Mészáros, no obscuro esteticismo de um Agamben, no cômico nonsense de Žižek ou nas incontinências verbais de um Olavo de Carvalho. Estamos condenados a pensar o hoje; mas em face

\footnotetext{
1 WEBER, Max. Economia e sociedade, vol. II. Brasília: Edunb, 1999, p. 580.

2 WEBER, Max. Escritos políticos. São Paulo: Martins Fontes, 2014, p. 385.
} 
do vazio de ideias contemporâneo, não nos resta outra saída senão buscar os clássicos de ontem. Chame-se a isso, se se quiser: aprender com a história.

A racionalização do mundo, tal como a descreveu Weber no preâmbulo do primeiro volume dos seus ensaios reunidos de sociologia da religião, não se concretizou. As grandes forças mobilizadoras deste processo (o direito, o capitalismo moderno, a ciência e a burocracia) nem sempre atuaram com o grau de integridade que se lhes atribuía.

Apesar de tudo isso, talvez se possa falar de uma weberianização do mundo. Num sentido muito preciso: o de uma gradativa mundialização de seu legado intelectual. Não apenas na condição de clássico das ciências sociais, mas também como um autor de cabeceira dos poderosos - de Theodor Heuss, o primeiro presidente da Alemanha após a catástrofe do nazismo, a FHC. De sua Alemanha natal à América Latina, dos Estados Unidos à Rússia, do leste europeu ao mundo árabe, o interesse pelo pensamento de Weber não encontra fronteiras nem padece do veto da história que se abateu sobre o marxismo após 1989.

Sendo assim, é apenas natural que, em julho de 2012, os institutos de humanidades alemães no exterior, há pouco rebatizados como Fundação Max Weber, tenham dedicado um simpósio internacional ao tema "Max Weber no mundo - Recepção e influência". O volume resultante, publicado em 2014, é o que nos cabe aqui resenhar. Estudos sobre a recepção de Weber não são propriamente uma novidade, todavia o interesse a respeito tem adquirido força, entre outras razões graças à redescoberta de Weber nos países que compunham o antigo mundo socialista.

"Max Weber em tempos de transformações", de Edith Hanke, abre o volume com um esboço de sociologia comparada da recepção da sociologia weberiana. A tese principal da autora é que o interesse por Weber tende a crescer especialmente em sociedades que passam por períodos de intensa transformação econômica, social e política (p. 2). Primeiramente, ela procede a uma avaliação do número de edições/traduções por país, o que nos revela algumas surpresas. A primeira delas é a liderança absoluta do Japão, com nada menos que 190 títulos entre 1925 e 2012. A carreira japonesa de Weber é, por assim dizer, inteiramente autóctone, deu-se sem intermediários. Mais que isso, os estudiosos daquele país produziram trabalhos sobre Weber que, vistos desde hoje, estavam muito à frente de seus congêneres anglo-saxões. Em 1981, Yoshiaki Ushida já criticava a perspectiva "a-histórica" da literatura internacional sobre Weber. Isso é tão mais impressionante se levarmos em conta que o início da publicação na Alemanha da edição crítica das obras de Weber (Max Weber Gesamtausgabe) só se iniciou em 1984. Hanke mostra ainda que, em países como Japão, Itália, Grécia e Coreia do Sul, as traduções mais 
recentes de Weber têm se baseado no gigantesco trabalho de erudição histórico-filológica da Gesamtausgabe. Poupemos ao leitor uma constrangedora comparação com o que, a esse respeito, se tem feito no Brasil.

Hanke identifica três tipos de transformação por detrás dos booms weberianos em diferentes países: (a) rápidas e drásticas mudanças de paradigmas científicos, (b) na estrutura socioeconômica e, por fim, (c) crises de legitimidade do ordenamento político. Tendo exercido o papel de pioneira (data de 1897 a tradução do opúsculo $A$ bolsa), a Rússia assistiu a uma virtual proscrição de Weber após a década de 1920. Tornou-se famosa a passagem da Grande Enciclopédia Soviética de 1951, em que Weber é chamado de "sociólogo, historiador e economista alemão reacionário, neokantiano, inimigo maldoso do marxismo" (apud p. 15). Na década de 1980, sobretudo a partir de 1990, com a derrocada do regime comunista e o fim do veto ideológico, a situação se inverte. Em curto espaço de tempo mais que dobra o número de obras de Weber disponíveis em russo.

Situação semelhante se observa na China, onde o advento do turbocapitalismo gerou uma demanda irrefreável por paradigmas alternativos. Graças aos esforços da germanista Rongfen Wang traduziram-se seções de Economia e sociedade, Confucionismo e taoísmo e as conferências Ciência como vocação e Política como vocação. A versão chinesa de A ética protestante e o espírito do capitalismo, publicada em outubro de 1986, esgotou-se em horas. Naquele mesmo ano, um jornal chinês publica uma entrevista com a sra. Wang com o significativo título "A febre Max Weber e a democratização política". Em 1989, tal situação se alteraria dramaticamente. Num colóquio realizado em julho de 2014 na Universidade de Erfurt, este resenhista teve a oportunidade de ouvir da própria sra. Wang o impressionante relato de como o auditório reservado para acolher o primeiro grande simpósio sobre Weber em Pequim acabou sendo usado como depósito militar tão logo estourou a repressão ao movimento estudantil na praça da Paz Celestial. O evento evidentemente não pôde ocorrer, frau Wang mora há anos na Alemanha e os chineses ainda esperam pela democracia.

Como o maoísmo não passa hoje, na China, de uma formalidade vazia na autoencenação do poder, não paira ali qualquer proibição formal a Weber e é revelador do espírito dos novos tempos que em 2006 A ética protestante tenha se tornado um verdadeiro best seller naquele país. Situação muito diferente da do Irã, em especial depois da derrota da "Revolução verde" de 2009. Edith Hanke (p. 20) mostra que Said Hajjarian, "que estava entre os mais próximos estrategistas do presidente reformista Khatami, foi ameaçado 
com a pena de morte também por difundir as teorias de Weber", e tendo de desculpar-se publicamente por isso.

O fato de Weber não ter produzido qualquer estudo sistemático sobre o islamismo decerto contribuiu para sua fraca recepção no mundo muçulmano, tema do ensaio de Stefan Leder (Max Weber in der arabischen Welt). Embora A ética protestante esteja disponível em árabe desde 1980, poucas traduções se seguiram. A recepção deve ali muito ao impulso de comentaristas franceses como Julian Freund, Colliot-Thélène e Philippe Raynaud. De forma geral, porém, Leder constata a inexistência de uma "confrontação produtiva com Max Weber" (p. 27). As razões não seriam apenas de natureza intelectual, posto que refletiriam também a ausência de uma relação dialética entre racionalismo prático (intramundano) e a ética religiosa islâmica. A conexão presente em toda a obra de Weber entre valores religiosos e a dinâmica da vida político-econômica, não se revelaria naquelas culturas uma chave heurística tão fértil quanto o foi no Ocidente.

Alexandre Toumarkine mostra, em "The introduction of Max Weber's thought and its uses in Turkey", que a Turquia diverge do padrão descrito acima. O autor evoca o interessante caso de Kayseri, uma capital de província famosa por seu tradicionalismo religioso e dinamismo empresarial. Um antigo prefeito da cidade, Şükrü Karatepe, chegou a declarar que, "para entender Kayseri, é preciso ler Max Weber" (apud p. 33). A possível existência de um islamic calvinism gerou um amplo debate na imprensa turca. Tornavamse evidentes os resultados a que chegaram diversos pesquisadores, para os quais "a fé islâmica não é um obstáculo ao desenvolvimento econômico ou à modernização social" (p. 34). É interessante notar que a Turquia tem uma história de recepção análoga à do Brasil sob vários aspectos: a defasagem temporal em relação a outras comunidades intelectuais, a importância dos imigrados de origem germânica (Alexander Rüstow e Gerhard Kessler tiveram ali um papel similar ao de Otto Maria Carpeaux e Emílio Willems entre nós), a influência exercida pela tradução de livros como As etapas do pensamento sociológico de Raymond Aron, e a coletânea From Max Weber de Gerth e Mills. ${ }^{3}$ As apropriações de Weber na ciência social turca giram em torno de questões como a aplicabilidade do conceito de carisma a Ataturk, o fundador da república, e ainda à permanência de um forte componente patrimonialista

\footnotetext{
Cf. MATA, Sérgio da. Modernity as fate or as utopia: Max Weber's reception in Brazil. Max Weber Studies, v. 16, 2016, p. 51-69; VILLAS BÔAS, Glaucia. A recepção controversa de Max Weber no Brasil (1940-1980). Dados. Revista de Ciências Sociais, v. 57, n. 1, 2014, p. 5-33.
} 
naquele país. Para o historiador Halil Inalcik o Estado turco constituiria um caso extremo de patrimonialismo, chamado por Weber de sultanismo. Inalcik teria demonstrado que "a fusão entre poder político e espiritual na pessoa do sultão fez do Império otomano o tipo perfeito de sultanismo" (p. 46).

O weberianismo no islã é objeto de outro capítulo, "Max Weber and the revision of secularism in Egypt". O autor, Haggag Ali, expõe as discussões que intelectuais egípcios têm feito nos últimos anos sobre a "secularização" numa chave weberiana. Atenção especial é dada à monumental Enciclopédia dos judeus, judaísmo e sionismo escrita por Abdel-Wahab El-Messiri (1938-2008), em que se faz uma distinção entre "secularismo parcial" e "secularismo compreensivo", sendo o primeiro uma modalidade mais branda (e que El-Messiri acreditava ser compatível com o Islã), e o último uma forma mais radical de desencantamento do mundo. É interessante notar que o que adquiriu centralidade na recepção de Weber no Egito é talvez o aspecto mais frágil de sua visão da modernidade, qual seja, o conceito mesmo de "secularização". Mas nada se compara ao mal-entendido que atribui a Weber a ideia de que somente no Ocidente teria havido racionalização, e que Haggag Ali repete um tanto acriticamente. Sob a influência da legenda segundo a qual a racionalização conduziu ao holocausto - é preciso desconhecer um livro como Mein Kampf para se estabelecer uma relação entre uma coisa e outra -, El-Messiri difunde em seu país um mal-entendido em cuja origem, curiosamente, está o antimodernismo judaico presente em autores como Horkheimer e Bauman. Sua preocupação maior era fazer um diagnóstico histórico-sociológico do sionismo, visto como "uma ideologia secular que aspira à salvação dos judeus, prometendo a seus adeptos (...) o fim das perseguições e do sofrimento no aqui-e-agora" (p. 57).

"Max Weber in the world of Empire" é o título da contribuição de Sam Whimster. Trata-se de situar Weber no contexto da época áurea do imperialismo, bem como as possíveis ressonâncias disso para sua obra. Com base em cartas inéditas até então, Whimster mostra a evolução das ideias de Weber a respeito das aspirações de grandeza da Alemanha - contudo não estamos certos de que ele de fato "olhava para o mundo através das lentes do império, mais que das do estado-nação" (p. 77). Excetuada a forte influência dos junkers, não há dúvida de que Bismarck e a Prússia das décadas de 18701890 permaneceram como uma espécie de modelo para Weber durante quase toda sua vida. Entretanto, é revelador que o conceito de imperialismo não seja definido com mais clareza por Whimster, o que lhe permite - assim nos parece - empregar o termo com uma liberdade demasiada, e assim classifi- 
car Weber como um "imperialista". Sinceramente, não nos vem à memória algum texto deste autor que dê ensejo a tal classificação.

Seguem-se dois importantes estudos sobre a Rússia e a Polônia. O primeiro deles, da autoria de Dittmar Dahlmann (p. 81-102), examina o interesse de Weber pelo enigma russo, assim como o papel da Rússia em sua obra. Mantendo estreita relação com a comunidade eslava em Heidelberg, Weber publicou dois longos estudos sobre a fracassada revolução liberal de 1905 naquele país, e seu conceito de "pseudoconstitucionalismo" tornou-se influente nos meios jurídicos russos antes da ascensão dos bolcheviques. Cabe notar ainda que não foram sociólogos, mas historiadores (Dimitri Petrusevski, Nicolai Kareev, Alexandr Neusychin) os que deram início à recepção russa de Weber. Em artigo de 1923, Neusychin defendeu inclusive a tese, que nos inclinamos a abonar, de que a sociologia weberiana nada mais é que "a história traduzida na linguagem dos conceitos gerais" (apud p. 87). Igualmente curioso é o fato de que alguns excertos de $A$ ética protestante e da Ética econômica das religiões mundiais tenham sido traduzidos e publicados no período soviético, precisamente num número de 1928 de uma revista chamada Ateísta. De resto, prevaleceu o veto ideológico a Weber. Uma tradução de $A$ ética protestante chegou a ser feita em 1972 por Neusychin, mas como levava um selo com as palavras "apenas para o uso interno", evidentemente não pôde ser publicada. Desnecessário dizer que uma Weber-renaissance digna desse nome teria de esperar pela Glasnost e pela derrocada definitiva do aparato de poder em 1990.

Marta Bucholc se dedica ao espinhoso capítulo polonês da weberianização do mundo em seu estudo "A reação dos sociólogos poloneses aos escritos de Max Weber sobre a Polônia". Relação espinhosa nem tanto pelo fato de este país ter se tornado parte da Cortina de Ferro, mas porque as poucas menções de nosso autor aos poloneses estão entre as mais infelizes que ele escreveu. ${ }^{4}$ A ponto de ele próprio admitir em 1916: “Eu era tido como um inimigo da Polônia. Preservo ainda hoje uma carta assinada e enviada de Lemberg há vinte anos, em que se lamentava que meus antepassados não tivessem sido comidos por um porco mongol" (apud p. 111-112). O fato é que não houve influência alemã digna de nota sobre os pais fundadores da sociologia polonesa, Stefan Czarnowski e Florian Znaniecki, os quais rever-

\footnotetext{
4 WEBER, Escritos políticos, op. cit., p. 3-36.
} 
beravam uma nítida ascendência francesa. Segundo Bucholc, esta situação não se alterou desde então.

Traduções de Weber em polonês só surgiram no alvorecer do século XXI. Mas mesmo com o advento da open society, observa Bucholc,

os escritos políticos de Weber provavelmente eram percebidos como irrelevantes na nova realidade da integração europeia, na qual Polônia e Alemanha há muito mantinham relações amigáveis (...). Os escritos políticos de Weber sobre a Polônia seriam então não apenas muito difíceis de se ler e de maneira alguma aceitáveis, mas seriam também desinteressantes (p. 118).

Caso inteiramente diverso e sob todos os aspectos digno de atenção nos é apresentado por Wolfgang Schwenkter em "Controvérsias japonesas sobre A ética protestante de Max Weber". Um dos mais competentes estudiosos das relações intelectuais entre Japão e Alemanha, Schwenkter enumera em seu bem documentado ensaio as razões da ascendência japonesa nos estudos weberianos. A carreira japonesa de Weber deve muitíssimo a eruditos devotados à história econômica (Fukuda Tozuko, Kawada Shiro e Hani Goro). Não menos importante foi a passagem pelo Japão de autores influenciados por Weber, tais como Karl Löwith e Robert Bellah. Para que se tenha noção da singularidade do caso em tela, basta dizer que, desde 1964, existe uma versão japonesa integral de $O$ judaísmo antigo. Praticamente toda a obra de Weber acha-se hoje traduzida naquele país, algo com que o pobre leitor brasileiro só pode sonhar. Em seu diagnóstico da situação atual, Schwenkter mostra que a chegada das teorias pós-modernas ao Japão se articula com o surgimento de uma nova geração de intelectuais japoneses que questionam - como é justo que seja - a atualidade do legado de Weber. O autor examina ainda a grande polêmica gerada em 2002 pela publicação de livro do sociólogo Hanyu Tatsuro, $O$ crime de Max Weber. O "crime" em questão assenta no uso pouco rigoroso que Weber fez de certas fontes bíblicas na Ética protestante. Raramente se terá empregado uma terminologia tão forte numa querela essencialmente filológica, mas no final das contas há que dar razão a Schwenkter por sua crítica a Tatsuro por se valer de um título "inteiramente absurdo" por razões mercadológicas (p. 140).

Nos quatro ensaios seguintes de Max Weber in der Welt o leitor familiarizado com os estudos weberianos não consegue manter o mesmo nível de atenção. Ora o tratamento dos problemas não se aprofunda o suficiente, ora os resultados apresentados são magros demais para recompensar o esforço de leitura. Em "A estadia romana (1901-1903) e a relação de Max Weber com o ca- 
tolicismo", Peter Hersche trata de uma questão potencialmente relevante, mas para a qual, ao fim e ao cabo, nenhuma evidência nova chega a ser aportada.

Em "The American journey and the protestant ethic", Lawrence Scaff oferece uma síntese de sua alentada monografia Max Weber in America (2011), revisitando os topoi da experiência americana de Weber: da longa viagem empreendida com sua esposa em 1904 à importância de nomes como Parsons e Edward Shils ou de instituições como as Universidades de Chicago, Columbia e a New School na recepção de sua obra. Scaff sublinha dois pontos que parecem mesmo relevantes. Por um lado, o impacto da viagem aos Estados Unidos sobre a redação da segunda parte da Ética protestante; de outro, o fato de que sua recepção norte-americana jamais teria sido a mesma, caso este escrito não oferecesse uma espécie de narrativa mestra do American dream.

Quanto ao ensaio "Max Weber e a Philosophie de l'art de Hippolyte Taine", de Francesco Ghia, este parecerista não encontrou razões para traçar qualquer comentário a respeito, dado o seu caráter altamente especulativo e inconclusivo. Melhor seguir em companhia de Hinnerk Bruhns e seu capítulo "Max Weber na Guerra Mundial (1914-1920) - Com uma olhadela da França". No país da escola durkheiminiana, a introdução do pensamento de Weber jamais teria sido algo fácil. Por muito tempo, intelectuais como Raymond Aron e Julian Freund amargaram uma solidão de mil desertos. A lentidão com que apareceram as traduções francesas é de fato impressionante. Até o ano de 2014 não havia uma versão francesa da pioneira biografia publicada por Marianne Weber em 1926. Bruhns explora a experiência de Weber na Primeira Guerra Mundial - ele foi encarregado de administrar os hospitais da região de Heidelberg - e como as vivências daquele período se traduzem em seus escritos posteriores. É sabido que Weber saudou o conflito entusiasticamente, sem, porém, aderir ao Hurrapatriotismus de um Max Scheler ou dos signatários do famoso manifesto "Ao mundo cultural", em que eruditos alemães de prestígio defenderam as ações do exército alemão. Não é pequeno, em todo caso, o papel do fenômeno "guerra" na sua sociologia, e ninguém duvida que, ao definir a política como "luta", ele pavimentou uma perspectiva do político que atingiria seu ápice em Carl Schmitt.

Chegamos finalmente ao último ensaio do volume, "Max Weber e os problemas histórico-universais da modernidade", de Gangolf Hübinger (p. 207-224). O autor faz um criativo exercício de análise da modernidade entendida enquanto um estágio da vida social marcado antes de mais nada pela aceleração civilizacional e pela tensão crescente entre visões seculares e religiosas de mundo (p. 208) - a partir das pistas deixadas por Weber em seus escritos. Hübinger distingue na sua obra quatro indicadores fortes do 
caminho alemão para a modernidade: o advento e afirmação do capitalismo, a crítica do historicismo, a cultura de massas e a democracia. Nas seções seguintes de seu capítulo, Hübinger trata de iluminar cada uma dessas variáveis à luz da erudição histórica e, sobretudo, de mostrar como o legado intelectual e científico de Weber constitui um lócus privilegiado para visualizarmos cada um desses processos. Tanto do ponto de vista econômico quanto do científico, cultural e político, o pensamento weberiano se presta, como poucos de seu tempo e posteriores a ele, a iluminar uma época que - a despeito de toda doxa pós-moderna - ainda não deixamos para trás.

Nesse sentido, e ao menos enquanto as quatro estruturas acima evocadas se mantiverem, o lugar de Max Weber no grande museu das antiguidades intelectuais do Ocidente permanecerá vazio. Ele continuará incontornável para nós, no sentido preciso daquele termo que volta e meia surge em seus escritos, a saber: como destino.

\section{Referências bibliográficas}

MATA, Sérgio da. Modernity as fate or as utopia: Max Weber's reception in Brazil. Max Weber Studies, v. 16, 2016, p. 51-69.

VILLAS BÔAS, Glaucia. A recepção controversa de Max Weber no Brasil (19401980). Dados. Revista de Ciências Sociais, v. 57, n. 1, 2014, p. 5-33.

WEBER, Max. Economia e sociedade, vol. II. Brasília: EdUnB, 1999.

WEBER, Max. Escritos políticos. São Paulo: Martins Fontes, 2014. 